\title{
Physiological Responses to Virtual Exergame Feedback for Individuals with Different Levels of Exercise Self-Efficacy
}

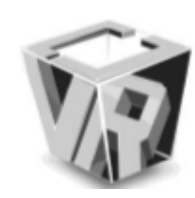

Jessica E Cornick 1, Jim Blascovich 1

1 University of California, Santa Barbara

Abstract - OBJECTIVE: Exercise videogames are increasingly popular as individuals seek to increase their activity. This study assessed the interaction of exercise self-efficacy (ESE) levels and perceived task demands of a virtual game on exercise and physiological reactions. Perceived task demands were manipulated by changing parameters of the participant's avatar in the exergame.

METHODOLOGY: An experimental design was used with 89 female undergraduate students (Mean age $=18.74 \pm 1.05,18$ to 21 years) who were randomly assigned to the high task demand condition (avatar weight remaining constant) or low task demand condition (avatar losing weight). Prior to the biking task, the Exercise Self-Efficacy scale was used to measure ESE.

Participants biked on a stationary bike while immersed in a virtual environment with an avatar and were told the avatar would slim if they cycled fast enough. Only half of participants' avatars actually slimmed (high task demand manipulation). During biking, cardiovascular measures were assessed using a Biopac MP150 system with an Impedance Cardiograph and CNAP Monitor 500. One week after completion of the study, participants reported amount of exercise completed in the last week (in $\mathbf{1 5}$ minute increments) via the Physical Activity Questionnaire. Moderated regressions and moderated mediation models were used to examine the interaction of ESE levels, experimental condition and cardiovascular reactivity on amount of strenuous physical activity.

RESULTS: Individuals with high ESE showed similar results in both task demand conditions with physiological reactivity patterns indicative of threat. Individuals with low ESE with a static avatar completed less exercise than those with low ESE with a slimming avatar.

CONCLUSION: Results confirm that individuals with low ESE are particularly vulnerable to exercise demands.

Index Terms - Biopsychosocial Model of Challenge and Threat; Self-Efficacy; Exercise; Exergame.

\section{INTRODUCTION}

The United States is facing an obesity "epidemic" (Callahan, 2013) with many clinicians, researchers and doctors citing the lack of regular exercise as a leading contributor (Kaminsky et al., 2013). According to the Centers for Disease Control (CDC), adults should complete 2.5 hours of aerobic exercise at a moderate level per week, 
but only $48 \%$ of US adults meet this guideline (Centers for Disease Control, 2012). While many people know exercise is important for maintaining a healthy weight and lifestyle, many do not perform the recommended amount because they find it difficult, boring, or hard to schedule (Johnston, Massey, \& DeVaneaux, 2012). To make exercise more enticing and enjoyable, companies like Microsoft and Sony have designed exercise based videogames that mentally and physically engage the user. Although these exergames have proven to be popular and lucrative for their respective companies, research on the effectiveness of these exergames has been mixed, with some showing negative consequences of use (Song, Kim, \& Lee, 2011). In the current research, we tested the hypothesis that perceived task demands during an exergame interacts with an individual's exercise self-efficacy level to influence cardiovascular responding and future exercise levels (see Figure 1).

We first provide a review of exercise selfefficacy and self-efficacy more broadly, followed by a review of the literature on exergames and how the outcome of exergame use is influenced by exercise self-efficacy. Finally, we present an overview of the biopsychosocial model of challenge and threat (Blascovich, Mendes, Vanman, \& Dickerson, 2011) as a means for assessing reactions to perceived exergame task demands.

\subsection{Self-Efficacy and Exercise Self- Efficacy (ESE).}

Most people strive to see themselves as generally good, efficacious, and able to effect change in the world around them (Taylor \& Brown, 1988). An individual's belief that he or she has the ability to successfully complete tasks and accomplish goals reflects his/her level of self-efficacy (Bandura, 1982). Selfefficacy evaluations influence many aspects of an individual's life including cognitive, motivational, and affective processes. Individuals who perceive themselves to be more efficacious set more challenging goals, quickly recover after failure, experience less stress, and approach difficult tasks with a mastery orientation (Bandura, 1994).

Individuals consider many sources of information when assessing the amount of efficacy felt for a specific task including the appraisal and integration of past accomplishments, social and verbal persuasion and feedback, vicarious experiences, and physical and emotional states (Bandura, 1977; Samson \& Solomon, 2011). An individual's level of self-efficacy for a given task reflects the level of difficulty he/she believes they can overcome successfully (Bandura, 2006). Although many elements influence efficacy levels, research indicates that an individual's general efficacy level is relatively stable over time (Chen, Gully, \& Eden, 2001; Strecher, McEvoy, Becker, \& Rosenstock, 1986). However, if individuals are faced with information that calls into question their efficacy for a given task, one way they may maintain self-efficacy is to re-evaluate task demands and available resources such that the level of demands is equal to or less than available resources (Chemers, $\mathrm{Hu}$, \& Garcia, 2001; Feltz, Short, \& Sullivan, 2008).

Even as individuals have feelings of general efficacy (the capability to behave in a way that influences events; Bandura, 1994), Bandura (2006) clearly states that individuals also have specific efficacy levels for a variety of tasks, including exercise. Exercise selfefficacy (ESE) is an individual's belief that he or she can complete an exercise routine even in the face of stressors or detractors (Bandura, 2006). Hence, ESE levels are generally associated with perceptions of greater resources relative to situational demands, allowing for adaptive coping with potentially stressful stimuli (Chemers et al., 2001; Jones, Meijen, McCarthy, \& Sheffield, 2009). High ESE levels are also associated with a host of daily positive outcomes and behaviors including persisting longer at physical tasks, exercising more, being more likely to pursue challenging goals, cope with pain, and persevere through setbacks (Chuang, Chang, Lee, Chou, \& Doong, 2003; 
Hankonen, Absetz, Ghisletta, Renner, \& Uutela, 2010; Hutchinson, Sherman, Martinovic, \& Tenenbaum, 2008; Llewellyn, Sanchez, Asghar, \& Jones, 2008).

\subsection{ESE and Exergames.}

Exergames, or exercise video games, come in many forms including Dance Dance Revolution, the Wii Fit suite, Zumba for PlayStation, and many more (see Cornick \& Blascovich, 2016 for a review). Exergame platforms vary widely in the type of user input used to track movement from joystick to infrared camera to weight sensitive pressure pad. What is common among all types of exergames however is that game progress is measured by the amount and type of movement generated by the user.

Even though exergames have only recently become commonplace in American homes, much research points to their benefits over more traditional exercise routines (Rizzo, Lange, Suma, \& Bolas, 2011). For example, exergames allow users to review their movements for accuracy as well as obtain different perspectives of their avatar from multiple viewing angles. These inherent exergame functions have been shown to increase the accuracy of newly learned exercise movements (Bailenson et al., 2008).

Use of exergames has also been shown to increase intense exercise, intrinsic motivation, energy expenditure, positive mood, and energy levels for both children and adults (Chuang et al., 2003; Fox \& Bailenson, 2009; Gao, Chen, Pasco, \& Pope, 2015; Ijsselsteijn, de Kort, Westerink, de Jager, \& Bonants, 2006; Legrand, Joly, Bertucci, Soudain-Pineau, \& Marcel, 2011; Lyons, Tate, Komoski, Carr, \& Ward, 2012; Plante, Aldridge, Bogden, \& Hanelin, 2003; Plante, Cage, Clements, \& Stover, 2006; Russell \& Newton, 2008). Researchers have posited that exergames influence these health outcomes because of the "Proteus Effect," or the idea that avatar behavior can inform a user's attitudes, motivations, and goals, and ultimately change the user's behavior in everyday life (Yee, Bailenson, \&
Ducheneaut, 2009). For example, users whose avatars engage in healthy behaviors in Second Life are more likely to engage in exercise and other active behavior than users who have avatars that are less physically active (Dean, Cook, Keating, \& Murphy, 2009). Similarly, engaging with an avatar in Second Life (compared to a 2D social networking site or a control condition) improved exercise efficacy and supported weight loss behaviors (Behm-Morawitz, Lewallen, \& Choi, 2016).

Research during the last decade suggests that using exergames can also influence ESE levels. For example, Katula and McAuley (2001) conducted a study in which healthy participants exercised in front of or in the absence of a mirror. Compared to the no mirror condition, participants in the mirror condition reported increases in ESE immediately post exercise and twenty minutes later. However, other research has found that women who perceive themselves to be overweight who exercised in front of a mirror had a maladaptive cardiovascular response pattern, decreased work output, and decreased ESE relative to women who exercised without the mirror (Cornick \& Blascovich, 2015; Katula, McAuley, Mihalko, \& Bane, 1998). Similarly, Song and colleagues (2014) found in their study of normal and slightly overweight individuals, that participants who were dissatisfied with their weight and played an exercise video game while seeing themselves on a television screen experienced decreased ESE, and decreased enjoyment following exercise (Simonavice, 2008; Song, Kim, \& Lee, 2014; Song, Peng \& Lee, 2011). These results underscore findings that perceptions of weight influence both psychological and physical outcomes during exercise.

Although these results appear contradictory, the results can be explained by the presence or absence of heightened self-awareness in the user. The self directed awareness elicited by mirrors, exergames, and standing in front of a crowd increase levels of self-evaluation and decrease levels of self-efficacy by 
making the discrepancy between an individual's "ideal" and actual self more salient (Ginis, Jung, \& Gauvin, 2003; Mead, 1934; Wickland \& Duval, 1971). Discomfort is associated with awareness of the disparity between current and ideal selves and the discomfort grows proportionally with the discrepancy, motivating individuals to reduce the discrepancy (Higgins, 1989). Such motivation may consequently make the demands associated with reaching the goal more salient. Therefore, individuals with increased self-awareness during performance tasks should perceive increased demands when compared to less self-aware individuals. Evaluations of situational demands and personal resources play a central role in cardiovascular $(\mathrm{CV})$ reactivity to stressful tasks (as outlined by the biopsychosocial model of challenge and threat) that ultimately influences an individual's ESE level.

\subsection{Biopsychosocial Model of Challenge and Threat.}

The biopsychosocial model of challenge and threat (BPSCT) states that individuals exhibit varying patterns of psychophysiological reactions to stimuli based on their implicit and explicit evaluations of task demands and personal resources to meet those demands (Blascovich, 2008; Blascovich \& Mendes, 2010). When individuals ascertain (either consciously or unconsciously) that they have greater resources than a performance task demands, they exhibit patterns of $\mathrm{CV}$ reactivity indicative of challenge. Conversely, if they ascertain that they do not have enough resources to meet task demands, they exhibit $\mathrm{CV}$ reactivity patterns indicative of threat. States of challenge and threat can be differentiated using four $\mathrm{CV}$ measures: heart rate (HR; number of heart beats per minute), ventricular contractility ( $\mathrm{VC}$; a time based measure of the time from the left ventricle contracting to the opening of the aortic valve), cardiac output ( $\mathrm{CO}$; the amount of blood ejected by the heart per minute), and total peripheral resistance (TPR; overall resistance in the vasculature (arteries, veins, etc.) of the body; cf. Blascovich et al., 2011).
Electrocardiography (ECG), continuous mean arterial blood pressure (MAP) measurement, and impedance cardiography (ICG) are used to quantify these four measures. In addition to the four standard metrics, the current study also assessed rate pressure product (RPP) which is a metric of both energy consumption of the heart and stress in the cardiac muscle (Smith \& Fernhall, 2010). Unnecessary effort and strain placed on the heart can have negative consequences for the $\mathrm{CV}$ fitness of threatened/stigmatized individuals (Blascovich, Mendes, Hunter, Lickel, \& Kowai-Bell, 2001; Kelsey, 2004).

The BPSCT specifies that in a motivated performance situation (i.e., one requiring active coping in which actions can be evaluated, like giving a speech to a panel of raters), sympathetic neural activation results in increases in myocardial ventricular contractility (VC i.e., pre-ejection period $\left.(\mathrm{PEP})^{*}-1\right)$ and HR. This reactivity pattern is common to both challenge and threat motivational states demonstrating that the individual is engaged in the motivated performance task. Given task engagement, when an individual's resources meet task demands (state of challenge), increases in released epinephrine cause decreases in arterial contractility resulting in lower TPR and increased CO. During a state of threat (evaluation of fewer resources compared with demands), cortisol is released in addition to the epinephrine resulting in little change or an increase in TPR and little change or decrease in CO (Blascovich, 2008; Mendes, Blascovich, Lickel, \& Hunter, 2002). Although this pattern of physiological responding may be relatively harmless in the short term, the pattern of physiological responding to stressful stimuli is a significant predictor of an individual's future $\mathrm{CV}$ disease risk and CV health (Kelsey, 2004). Additionally, changes in these indexes have been shown to predict concurrent and future physical and cognitive performance in a variety of domains (see Blascovich, 2008; Blascovich \& Mendes, 2010; Tomaka, 
Blascovich, Kelsey \& Leitten, 1993; Tomaka, Blascovich, Kibler, \& Ernst, 1997).

Crucial to the current study, research testing the BPSCT during metabolically demanding tasks has shown that the CV system works harder but less efficiently for individuals experiencing greater task demands (Rouselle, Blascovich, \& Kelsey, 1995). In their study, participants pedaled a stationary bike while simultaneously doing serial subtraction aloud showed greater $\mathrm{CV}$ response $(\mathrm{CO}, \mathrm{VC}$ and HR) than during either task conducted alone (Rouselle et al., 1995). Similarly, when participants were asked to ride a stationary bike in front a mirror (versus no mirror), they exhibited threat reactivity profiles in reaction to the increased task demands and decreased personal resources associated with exercising in front a mirror (Cornick \& Blascovich, 2015).

Combining knowledge from the BPSCT and exercise physiology literature, we predict that individuals exercising in a physiologic state of threat would exhibit a simultaneous increase in TPR and a decrease in CO, resulting in active muscles receiving less oxygenated blood. When muscles do not receive enough oxygen needed to produce adenosine triphosphate energy, lactic acid is produced, which accumulates in the blood stream signaling the need for anaerobic metabolism (Rowell, Taylor, Wang, \& Carlson, 1964). Periods of anaerobic metabolism can be maintained for short periods of time (around a minute) before the individual fatigues, and during anaerobic metabolism carbohydrate stores are metabolized instead of fat stores in order to use available blood oxygen most efficiently (Wasserman et al., 2004). By extension, it follows that individuals who exercise while in a state of threat place more stress on the heart, derive fewer $\mathrm{CV}$ and fat burning benefits, and cannot exercise as long as individuals in a state of challenge (Kelsey, 2004; Rowell et al., 1964; Wasserman et al., 2004).

\section{AIM OF THE PROJECT}

Exercise self-efficacy levels are known to predict a host of positive daily outcomes by increasing perceived available resources. Individuals with high ESE levels perceive more available resources than individuals with low ESE levels (Chemers et al., 2001; Samson \& Solomon, 2011). Additionally, although exergames are useful in that they encourage individuals to exercise, research on exergames and ESE suggests that increased self-awareness brought on by use of the exergame can make task demands more salient (Katula \& McAuley, 2001; Song et al., 2011; Song et al., 2014). When tasks are relatively easy, an individual perceives low task demands; the opposite is true of more difficult tasks. The perceived ratio of personal resources and task demands determines whether an individual experiences positive or negative outcomes from exercise via the BPSCT (Blascovich, 2008).

The current study explored the interaction of ESE and perceived exergame task demands on BPSCT indices and completed strenuous exercise in a sample of women who reported being heavier than their ideal weight. In the lab, participants cycled on an ergometer in a digital virtual environment with an avatar that either appeared to slim down (fewer task demands) or not (more task demands) during the cycling while physiological responses were recorded. One week later, participants reported their average amount of exercise completed during the intervening week.

We hypothesized that individuals in the avatar slimming condition (fewer task demands) would show no differences in CV responding and future exercise as task demands stay low regardless of whether the participant has low or high ESE (low or high perceived resources respectively). However, for those in the avatar constant condition (more task demands) with low ESE, we hypothesized that they would exhibit a CV reactivity profile of threat and would show low levels of exercise (low resources and high task demands). Finally, for those in the 
avatar constant condition (more task demands) with high ESE, we hypothesized that they would exhibit a $\mathrm{CV}$ reactivity profile of challenge and would show high levels of exercise (high resources and high task demands; see Figure 1 for a theoretical model). These hypotheses will be tested in two stages, Hypothesis A will test whether ESE and exergame task demands interact to influence CV reactivity, and Hypothesis B will assess the mediation of the relationship between ESE and strenuous exercise by CV reactivity.

Importantly, due to the metabolically demanding nature of the task, the threat pattern of $\mathrm{CV}$ responses was expected to occur during the latter minutes of the task (minutes 3 - 5; Rouselle et al., 1995). Additionally, in typical BPSCT studies in which the participant is doing a task that is cognitively based, threat is indexed by no change or an increase in TPR values. However, when the task is metabolically demanding (as is the case with riding a stationary bike), BPSCT research shows that all individuals show a reduction in TPR and threat now becomes indexed by smaller reductions in TPR values (Tomaka et al., 1997).

\section{METHODS}

\subsection{Participants.}

Eighty nine female undergraduates (44\% White, 22\% Hispanic/Latino, 19\% Asian American, $15 \%$ other or multiple ethnicities) from the Introductory Psychology and Experimental Psychology subject pool at the University of California, Santa Barbara (UCSB) were recruited to participate in exchange for course credit. The sample was restricted to women who perceived themselves to be above their ideal body weight. Perceived weight (versus their actual weight) was used as a selection metric as perceived weight normality is often more important in determining mental and emotional states (which contribute to selfefficacy levels) than actual weight and women who are above their ideal weight would be interested in losing weight via exercise and exergames as tested in this study (Bandura, 2006; Major, Hunger, Bunyan, \& Miller, 2014; Muennig, Jia, Lee, \& Lubetkin, 2008). Therefore, only women who initially rated their current weight as above "ideal" were recruited to participate in the current study.

Participants ranged in age from 18 to 21 $(M=18.74, S D=1.05)$ and their average body mass index (BMI) fell within the normal to obese range $(M=23.34, S D=3.63$, range $=$ 14.42-35.41). Based on the Centers for Disease Control guidelines, 3.6\% $(n=3)$ were underweight, $65.9 \%(n=56)$ were normal weight, $25.9 \%(n=22)$ were overweight, and $4.7 \%(n=4)$ were obese. Participants were screened for major heart conditions, medications, pregnancy, and other serious medical conditions.

\subsection{Design and Procedure.}

The current study involved two betweensubjects factors -- perceived exergame task demands (low or high task demands) and ESE level (continuous) - and one withinsubjects factor, time (5 minute Baseline 1, 5 minute Baseline 2, and 5 minute task). During the task, each participant cycled on an ergometer while immersed in a virtual environment. The two dependent measures were $\mathrm{CV}$ patterns and strenuous exercise completed the following week.

Prior to arrival at the laboratory, participants completed a measure of perceptions of ideal body weight and ESE. In order to avoid influencing the physiological measures, participants were also asked to abstain from caffeine for at least two hours prior to the study (Astrup et al., 1990). Upon arrival at the laboratory, participants who consumed caffeine were rescheduled for another time slot. Next, participants' height and weight were measured and CV leads and sensors were attached. Subsequently, the participant completed a seated, resting five-minute baseline period. The participant then sat on the ergometer and was immersed in the virtual environment (an exact replica of the laboratory). A second baseline period was 
conducted while participants sat on the ergometer without pedaling. The virtual world was then refreshed and participants were shown an avatar standing in the middle of the laboratory. Participants were told that the avatar "represents you and will reflect your hard work during the biking task. If you continue to pedal fast enough, she will lose weight." In actuality, only half of the participants completed the cycling task with an avatar that slimmed (a total of $15 \%$ of body width). The other half were assigned an avatar whose apparent weight remained constant throughout. Participants exercised at a constant 100-Watt workload for five minutes on an electronically-controlled upright pedacycle ergometer (Kettler Model E3; Rouselle et al., 1995). Finally, all sensors and leads were removed and participants were partially debriefed. One week later, participants were emailed a follow up survey that assessed daily average physical activity (Aahdahl \& Jorgensen, 2003). Participants' were then fully debriefed.

\subsection{Measures.}

Weight Perception. Perception of ideal body weight was measured via a single item during the pre-screening process. Participants were asked to rate themselves on a 1 to 7 scale, with "much thinner than ideal weight" at 1 , "at my ideal weight" at 4, and "much heavier than my ideal weight" at 7 . All participants rated themselves as a 5 or above $(5, n=45 ; 6$, $n=26 ; 7, n=11$ ). Participant's BMI and perceptions of ideal body weight were significantly correlated $(r(80)=.61, p<$ $.001)$.

Exercise Self-Efficacy. The Self-Efficacy to Regulate Exercise Scale (Bandura, 2006) required participants to rate how certain they were that they could perform their exercise routine three or more times per week given a number of common obstacles (e.g., "When I feel discomfort when I exercise", "If I don't reach my exercise goals"). All responses were given on an 11-point scale ranging from 0 (Cannot do at all) to 10 (Highly certain can do) after completing the stationary biking task. Reliability among items was (Cronbach's $\alpha=.94)$. An average ESE value was calculated by taking the mean value of all 18 items (ESE $M=5.27, S D=1.81$; see Table 1). Participant's ESE and BMI were significantly correlated $(r(83)=-.24, p<.05)$, such that participants with higher BMI reported lower levels of ESE.

Physical Activity Questionnaire. One week after completing the exergame in the virtual environment, participants completed the Physical Activity Questionnaire (PAQ; Aadahl \& Jorgensen, 2003) describing the total time spent on each of nine physical activity levels on an average day in the past week (24 hour total), 1-sleep or rest; 2 - sitting quietly or watching television; 3- working at a desk or eating; 4- standing or driving a car; 5- light cleaning or walking downstairs; 6biking to work or brisk walking; 7- gardening or carrying light objects upstairs; 8- aerobics or health club exercises; 9- running or racing at higher intensity than level 8 . Responses were reported in 15 minute increments. Although all nine levels were collected, the levels of most importance were levels eight and nine that correspond to high-energy expenditure behavior, so a composite score was created by adding level eight and nine activity (see Table 1).

Physiological Measures and Apparatus.

Physiological responses including heart rate (HR), stroke volume (SV), cardiac output (CO), pre-ejection period (PEP), and blood pressure (BP) were measured simultaneously, continuously, and noninvasively throughout baseline and task period via a Biopac MP150 system with an Impedance Cardiograph and CNAP Monitor 500. Impedance cardiograph (ICG) and electrocardiograph (ECG) recordings provided continuous measures of cardiac performance (SV, HR, and CO). Two pairs of mylar tape band electrodes (separated by at least three centimeters) encircled the participant's neck and torso (thorax at the xiphisternal junction; Sherwood et al., 1990). These provided basal trans-thoracic impedance $(\mathrm{Z} 0)$ data and the first derivative (dZ/dt) of pulsatile changes in transthoracic impedance, sampled at $1 \mathrm{kHz}$. The electrocardiograph recordings were obtained with a Modified Lead II configuration (the 
right lead below the clavicle and the left lead on the left side of the torso below the ribcage). A $400 \mu \mathrm{A}$ (rms) DC $50 \mathrm{kHz}$ current passed through the two outer electrodes and measured impedance from the two inner electrodes.

The CNAP Monitor enabled collection of continuous noninvasive recordings of $\mathrm{BP}$ from the participants' left thumb. Data were integrated via the MP150 and displayed and stored with Acqknowledge software (Biopac; Goleta, CA). Mindware software (Gahanna, $\mathrm{OH})$ was used to edit artifacts and ensemble and score the $\mathrm{CV}$ data in 60-s intervals. Four measures of cardiac performance (VC (PEP), $\mathrm{HR}$, TPR (derived from BP and $\mathrm{CO}$ ), and $\mathrm{CO})$ were used to distinguish between states of challenge and threat while RPP was assessed for its correlational strength with these four original measures. Scoring was performed blind to other participant data.

\section{RESULTS}

4.1 Preparation of Physiological Measures. Baseline Periods. To ensure there were no differences in participants' physiological responses during the rest periods as a function of experimental condition, multiple paired t-tests were performed comparing minutes 4 and 5 of baseline 1 and 2 across all five physiological indicators (HR, VC (PEP), CO, TPR, and RPP). Across all 30 comparisons, 11 reached statistical significance (using a $\mathrm{p}$ value of $\mathrm{p} \leq .05$, with baseline 1 values being lower). Because the baseline represents the lowest resting point, baseline values used in future analyses were created by averaging baseline 1 minute 4 and baseline 1 minute 5 for each index (five total baseline values were created, one for each index).

Reactivity Values. CV reactivity values were calculated by subtracting the baseline value from each of the five biking task physiologic values (HR, VC, CO, TPR, and RPP), for a total of five reactivity values per index (25 total).Values exceeding $\pm 2.6 \mathrm{SDs}$ from the mean $(p=.01$ in a normal distribution) were identified as extreme and were winsorized by assigning them a value
$1 \%$ higher (or lower) than the next-highest value (Tabachnik \& Fidell, 2013). Among the thousands of CV data points collected for this study, only 11 data points were winsorized.

Task Engagement. As task engagement is a pre-requisite for challenge and threat, we first examined whether participants were engaged in the biking task prior to testing for $\mathrm{CO}$ and TPR differences. Single-sample $t$-tests were used to assess whether HR and PEP reactivity values, which index task engagement (Blascovich, 2008), differed significantly from zero. In all task minutes in both exergame task demand conditions, task engagement was evidenced by significant increases in HR and VC reactivity (i.e., decreases in PEP from baseline) (all $t$ tests significant at $p<.05$ ).

\subsection{Hypothesis A- ESE and exergame task demands interact to influence $\mathrm{CV}$ reactivity.}

To test the interaction outlined in Figure 1 (ESE and exergame task demands condition on $\mathrm{CV}$ reactivity), moderated regressions were conducted on the last three task minute values for the five physiological indices, with ESE values and exergame task demands condition entered on step 1 and the interaction (product term) entered on step 2. It was hypothesized that participants in the low task demand condition (avatar slimming) would exhibit BPSCT reactivity profiles of challenge, while participants with low ESE in the high task demand condition (avatar constant) would display a threat response and participants with high ESE in the high task demand condition (avatar constant) would display a challenge response. See Table 1 for means and standard deviations for $\mathrm{CV}$ reactivity variables.

\subsection{Analysis of Physiologic Measures to Test Hypothesis A. \\ Cardiac output reactivity. At step 1 there} was no main significant main effect of exergame task demands condition $(b=.18, p$ $=.97)$ or $\operatorname{ESE}(b=1.69, p=.27)$. Together these two predictors explained $1.7 \%$ of the variance in $\mathrm{CO}$ reactivity, $F(2,72)=.62, p=$ .54 (adjusted R square $=1.0 \%$ ). 
At step 2, the interaction term $(b=-1.97, p=$ $.52)$ was non-significant and explained an additional $.6 \%$ of the variance in $\mathrm{CO}$ reactivity, $F(1,71)=.42, p=.52$.

Total peripheral resistance reactivity. There was a significant main effect of exergame task demands condition on TPR, $(b$ $=170.91, p<.05)$. Participants in the high task demand condition (avatar constant) showed TPR reactivity in line with a challenge response [simple $b=58.41, t(69)=$ $1.66, p=.10]$ while those in the low task demand condition (avatar slimming) showed TPR reactivity values in line with a threat response [simple $b=-23.10, t(69)=-.67, p=$ $.50]$. There was no main effect of ESE level on TPR values, $(b=16.84, p=.50)$. Together these two predictors explained $5.9 \%$ of the variance in TPR reactivity, $F(2,70)=2.20, p$ $=.12($ adjusted $\mathrm{R}$ square $=3.2 \%)$.

At step 2, there was a marginally significant interaction of exergame task demands and ESE level on TPR, $(b=-81.51, p=.10)$, which explained an additional $3.6 \%$ of the variance in TPR reactivity, $F(3,69)=2.42, p$ $=.10$. To follow up on this marginal interaction, we computed the simple slopes relating task demands to TPR at low and high levels of ESE. Participants with low ESE were strongly influenced by task demands in the low task demand condition (avatar slimming) they had smaller reductions in TPR (indicating a state of threat) compared to the high task demand condition (avatar constant) [simple $b=313.46, t(69)=2.58, p$ $<.01]$ contrary to our hypothesis. No such relationship emerged for individuals with high ESE [simple $b=28.13, t(69)=.23, p=$ .82] (see Figure 2).

Rate pressure product reactivity. There was a significant main effect of exergame task demands on RPP reactivity values, $(b=$ $1832.17, p<.01)$. Participants in the low task demand condition (avatar slimming) showed higher cardiac workload than participants in the high task demand condition (avatar constant). There was no main effect of ESE level on RPP reactivity, $(b=97.56, p=.51)$. Together these two predictors explained $10.2 \%$ of the variance in RPP reactivity, $F(2$,
70) $=3.99, p=.02$ (adjusted $\mathrm{R}$ square $=$ $7.7 \%)$.

At step 2, there was a significant interaction between exergame task demands and ESE level $(b=-1080.54, p<.01$; see Figure 3$)$, which explained an additional $10.3 \%$ of the variance in RPP reactivity, $F(3,69)=5.94, p$ $<.001$. Exercise self-efficacy level was an important factor for participants in the high task demand condition (avatar constant) [simple $b=648.71, t(69)=2.51, p<.01$ ] such that participants with high ESE had higher cardiac workload than participants with low ESE. Exercise self-efficacy levels were marginally related to RPP reactivity for individuals in the low task demand condition (avatar slimming) [simple $b=-431.83, t(69)$ $=-1.71, p=.09]$. Participants with low ESE had higher cardiac workload than participants with high ESE.

Finally, exergame task demands significantly impacted RPP reactivity values differently for participants with low ESE. Participants with low ESE in the low task demand condition (avatar slimming) had significantly higher cardiac workloads than participants in the high task demand condition (avatar constant) [simple $b=3721.99, t(69)=4.18, p$ $<$.001]. No such relationship emerged for individuals with high ESE [simple $b=-60.70$, $t(69)=-.07, p=.95]$.

\subsection{Hypothesis B- Relationship between ESE and exercise mediated by CV reactivity.}

To test the model outlined in Figure 1, moderated mediation models were conducted using the SPSS package PROCESS with 5000 bootstrap samples to generate $95 \%$ confidence intervals (Hayes, 2012). We hypothesized that the relationship between ESE and strenuous exercise would be mediated by $\mathrm{CV}$ reactivity, and that this mediated relationship would be moderated by exergame task demands condition. We hypothesized that individuals with threat CV reactivity patterns (smaller reduction in TPR and lower $\mathrm{CO}$ ) would show reduced strenuous exercise in the week following the 
experiment. We were also interested in how RPP reactivity values may influence exercise levels. As such, we also tested RPP in a moderated mediation model. We modeled three separate moderated mediation models: CO, TPR, and RPP (Hayes, 2015).

\subsection{Analysis of moderated mediations models to Test Hypothesis $B$.}

Cardiac output. The indirect effect of ESE on follow-up exercise through $\mathrm{CO}$ reactivity was not moderated by exergame task demands condition, index $=-.01,95 \%$ CI $[-$ $.11, .07]$ (Hayes, 2015). Additionally, CO reactivity did not significantly predict strenuous exercise $(b=.01, p=.19)$, and the relationship between ESE and strenuous exercise (total effect: $b=.28, p<.05$ ) was not mediated by $\mathrm{CO}$ reactivity (remaining indirect effect: $b=.25, p<.05)$. Taken together, these results suggest that $\mathrm{CO}$ reactivity alone does not explain exercise in the week after the experiment.

Total peripheral resistance. The indirect effect of ESE on follow-up exercise through TPR reactivity was not moderated by exergame task demands condition, index $=$ $.10,95 \%$ CI [-.22, .01] (Hayes, 2015). Additionally, TPR reactivity did significantly predict strenuous exercise in the following week $(b=.01, p<.05)$. Participants with more negative TPR reactivity (state of challenge) exercised more in the following week. Finally, the relationship between ESE and strenuous exercise $(b=.28, p<.05)$ was not fully mediated by TPR reactivity $(b=.24$, $p<.05$ ).

Rate pressure product. The indirect effect of ESE on follow up exercise through RPP reactivity was not moderated by exergame task demands condition, index $=-.04,95 \% \mathrm{CI}$ $[-.19, .12]$. Additionally, RPP reactivity did not predict strenuous exercise in the following week $(b=.01, p=.59)$. Finally, the relationship between ESE and strenuous exercise $(b=.28, p<.05)$ was not mediated by TPR reactivity $(b=.26, p<.05)$.

\section{DISCUSSION}

We hypothesized that individuals in the low task demands condition (avatar slimming) would show no differences in CV responding or exercise levels. However, for those in the high task demands condition (avatar constant) with low ESE, we hypothesized that participants would exhibit a CV reactivity profile of threat and would show low levels of exercise (few perceived resources and high task demands due to increased perceived task demands). For those in the high task demands condition (avatar constant) with high ESE, we hypothesized that participants would exhibit a CV reactivity profile of challenge and would show high levels of exercise (many perceived resources and high task demands due to increased perceived task demands). Finally, we hypothesized that the relationship between ESE and strenuous exercise would be mediated by $\mathrm{CV}$ reactivity, and that this mediated relationship would be moderated by exergame task demands condition.

Results deviated from our hypotheses but yielded interesting results. Individuals with high ESE (high perceived resources) had similar outcomes regardless of exergame task demands, higher threat response (TPR), and a modest amount of cardiac work (RPP). In contrast, participants with low ESE (fewer perceived resources) were significantly influenced by exergame task demands. Participants with low ESE in the low task demands condition (avatar slimming) had highest levels of threat responding (TPR) and the highest cardiac workload (RPP) while those in the high task demands condition (avatar constant) had the largest reduction in TPR (signaling challenge) and lowest levels of cardiac workload (RPP). This outcome is particularly surprising as one would presume that exergames are designed for individuals with low ESE and receiving positive feedback during play (via a slimmed avatar) would result in positive physiological responding (a challenge response). Prior work on the BPSCT has shown that having a high performing partner (in this study, the avatar) can result in threat responses due to upward social comparisons which may be why the women in this study with low ESE and a slimming avatar had a physiological 
response pattern indicative of threat (Mendes, Blascovich, Major, \& Seery, 2001). Alternatively, other work by Mendes and colleagues has shown that interacting with an expectancy violating partner can contribute to threat responding. In the current study, women with low ESE were told their avatar would lose weight but because of their low ESE levels, perhaps they did not actually expect their avatar to slim, so when it did, it caused an expectancy violation resulting in the documented threat response (Mendes, Blascovich, Hunter, Lickel, \& Jost, 2007)

Our findings support previous research that being able to see and track performance outcomes during exercise and exergames is not beneficial for all. For individuals with high ESE in our study, the exergame task demands did not influence their physiological responding. However, our differential findings for those with low ESE support the findings of Cornick and Blascovich (2015) and Song, Kim, and Lee (2014), which outlined negative effects for those with body dissatisfaction. As exercise self-efficacy levels are created via a combination of past accomplishments, feedback, vicarious experiences, and physical and emotional states, it is possible that participants with high ESE had more exercise related information to rely on when making assessments of their performance in the experimental task (Bandura, 1977; Samson \& Solomon, 2011). This may be why there were no significant differences by exergame manipulation for participants with high ESE but significant differences for those with low ESE.

Additionally, findings from the current study do not fully support initial research on the Proteus Effect which states that a user's attitudes, motivations, goals, and behaviors can be influenced by the behavior of his or her avatar (Yee et al., 2009). These findings present a more complicated story in that TPR predicted strenuous exercise in the following week, specifically, when participants felt "challenged" (as defined in the BSCT model; Blascovich et al., 2011), they completed more strenuous exercise. This outcome suggests that merely viewing an assigned avatar was not enough to change participant's future behavior as would be posited by the Proteus Effect (Yee et al., 2009). Instead, experiences with the avatar interact with previous participant specific information (in this case, ESE) to influence behavioral outcomes such as strenuous exercise.

As shown by previous research assessing BPSCT outcomes in metabolically demanding tasks (Cornick \& Blascovich, 2015; Rouselle et al., 1995), exercising while in a CV state of threat puts additive stress on the $\mathrm{CV}$ system while not providing more beneficial outcomes (such as increased oxygen intake or calorie expenditure). In the current study, participants in the low task demands condition (avatar slimming) with low ESE (low perceived resources) exhibited a CV profile of threat during the cycling task. While it was initially hypothesized that these individuals would exhibit a CV profile of challenge, perhaps they were in a state of threat because even low task demands are still higher than their available resources due to their low ESE levels. Given that ESE and BMI negatively correlate and one-third of American adults are obese (Ogden, Carroll, Kit, \& Flegal, 2014), many Americans could be influenced by the design and implementation of future exergames.

\subsection{Practical Recommendations.}

Going forward, the design of exergames should consider demands being placed on the user and strive to ensure that users at all skill and resource levels will be able to complete the game demands. Our findings support the assertion that perceived exergame task demands can have negative outcomes for those with low ESE by influencing perceptions of task demands and resources. As self-efficacy is influenced by components such as feedback and previous experience, it may be beneficial to keep the user's first few experiences with the exergame short and simplistic so as to build a bank of positive experiences from which the user can draw from in the future. In this way, perhaps the user's efficacy will be increased sufficiently 
so as to enable them to meet and defeat challenging exercise scenarios in the future. Additionally, the exergame could be programmed such that the user receives a high volume of positive feedback at the outset (again with the intention of building high ESE levels to use in future challenging scenarios). Feedback and role model information could also be collected via the extended social network of other players of the exergame providing additional resources for the user to rely upon.

\subsection{Limitations and Future Directions.}

Although the current study represents a distinctive combination of physiological indices, trait ratings, and behavioral measures, there are limitations that must be addressed. First, the physiological indices of RPP and CO did not significantly predict exercise completed in the following week even though self-efficacy theory argues that physiological and psychological states are used to assess and modify self-efficacy levels (Samson \& Solomon, 2011). We believe that this predicted relationship was not borne out in the data as the biking task completed in the lab was only one of many experiences the participants have had with exercise and so therefore could potentially be easily discounted when evaluating current ESE levels. In future work, we are planning a longitudinal study where participants return to the lab over many weeks in order to see if we can more definitively influence exercise levels via physiological response patterns. In this way, we hope to include more baseline information about the participants previous and current exercise levels so as to be able to better predict future exercise outcomes resulting from experimental manipulations.

Second, the data were collected on a university campus on mostly normal weight individuals. In future studies, we would like to have a sample with more weight variability so as to determine if weight influences the relationships between ESE, physiological response patterns, and exercise. We would also like to seek out more members from the community so as to utilize a more representative and diverse sample for future work.

Finally, the avatar that was used in the exergame was generic and not customized to each participant. It is thus possible that each participant identified to a different degree with the avatar. In future studies we would like utilize software such that each avatar could be completely customized to the participant, thereby increasing identification with the avatar and potentially enhancing the avatar's influence on the participant (Yee et al., 2009). Level of identification with the avatar could provide a new approach to understanding the downstream consequences of exergame use.

\section{CONCLUSION}

As long as the obesity epidemic remains a part of the US social landscape, weight loss techniques such as exercising with exergames will remain popular. The research presented in this paper assessed the interaction of ESE, and exergame task demands (operationalized by different characteristics of an assigned avatar) on $\mathrm{CV}$ reactivity, and how this interaction predicted later strenuous physical activity levels. Results suggest that while these games may be more entertaining and engaging for users when compared with traditional exercise options, for those with low ESE, the downstream consequences of playing these games may be negative.

As exercise is a key component to maintaining a healthy lifestyle, finding ways for individuals with body dissatisfaction and low ESE to exercise without increasing selfawareness will be critical. This study represents the first of its kind to integrate the BPSCT model with virtual exergames to understand immediate downstream peripheral nervous system reactions to psychological phenomenon experienced while digitally immersed in a virtual space. Going forward, companies could integrate more sensitive physiological feedback mechanisms within consoles of video games so as to tailor the experience uniquely for 
each player in the hopes of providing a positive, self-efficacy enhancing experience. These unique experiences will be more readily available as virtual reality hardware continues to saturate the consumer market at more affordable rates.

\section{REFERENCES}

[1]. Aadahl, M., \& Jorgensen, T. (2003). Validation of a new self-report instrument for measuring physical activity. Medicine and Science in Sports and Exercise, 35(7), 1196-1202. doi: 10.1249/01.MSS.0000074446.02192.1 4

[2]. Astrup, A., Toubro, S., Cannon, S., Hein, P., Breum, L., \& Madsen, J. (1990). Caffeine: A double blind, placebo-controlled study of its thermogenic, metabolic, and cardiovascular effects in healthy volunteers. American Journal of Clinical Nutrition, 51(5), 759-767. Retrieved from http://ajen.nutrition.org/content/51/5/75 9.abstract

[3]. Bailenson, J., Patel, K., Nielsen, A., Bajscy, R., Jung, S. H., \& Kurillo, G. (2008). The effect of interactivity on learning physical actions in virtual reality. Media Psychology, 11(3), 354376. doi: 10.1080/15213260802285214

[4]. Bandura, A. (1977). Self-efficacy: toward a unifying theory of behavioral change. Psychological Review, 84(2), 191-215. doi: 10.1.1.315.4567

[5]. Bandura, A. (1982) Self-efficacy mechanism in human agency. American Psychologist, 37(2), 122-147. doi: 10.1037/0003-066X.37.2.122

[6]. Bandura, A. (1994). Self-efficacy. In V. S. Ramachaudran (Ed.), Encyclopedia of human behavior (Vol. 4, pp. 71-81). New York, NY: Academic Press.

[7]. Bandura, A. (2006). Self-efficacy beliefs of adolescents. Charlotte, NC: Information Age Publishing.

[8]. Behm-Morawitz, E., Lewallen, J., \& Choi, G. (2016). A second chance at health: How a 3D virtual world can improve health self-efficacy for weight loss management among adults. Cyberpsychology, Behavior, and Social Networking, 19(2), 74-79. doi: 10.1089/cyber.2015.0317

[9]. Blascovich, J. (2008). Challenge and threat. In A.J. Elliot (Ed.), Approach and Avoidance Motivation (pp. 431444). New York, NY: Taylor \& Francis.

[10]. Blascovich, J., \& Mendes, W.B. (2010). Social psychophysiology and embodiment. In S.T. Fiske, D.T. Gilbert, G. Lindzey (Eds.), Handbook of Social Psychology, (5 ${ }^{\text {th }}$ ed., Vol. 2, pp. 194-227). Hoboken, NJ: John Wiley \& Sons Inc.

[11]. Blascovich, J., Mendes, W. B., Hunter, S. B., Lickel, B., \& Kowai-Bell, N. (2001). Perceiver threat in social interactions with stigmatized others. Journal of Personality and Social Psychology, 80(2), 253-267. doi: 10.1037/0022-3514.80.2.253

[12]. Blascovich, J., Vanman, E., Mendes, W. B., \& Dickerson, S. (2011). Social psychophysiology for social and personality psychology. Thousand Oaks, CA: Sage Publications.

[13]. Callahan, D. (2013). Obesity: chasing an elusive epidemic. Hastings Center Report, 43(1), 34-40. doi: 10.1002/hast.114

[14]. Centers for Disease Control. (2012). Vital signs. More people walk to get better health (Publication No. CS233690-B). Retreived from http://www.cdc.gov/vitalsigns/pdf/2012 -08-vitalsigns.pdf

[15]. Chemers, M.M., Hu, L., \& Garcia, B.F. (2001). Academic self-efficacy and first-year college student performance and adjustment. Journal of Educational Psychology, 93(1), 55-64. doi: 10.1037/0022-0663.93.1.55

[16]. Chen, G., Gully, S. M., \& Eden, D. (2001). Validation of a new general selfefficacy scale. Organizational Research Methods, 4(1), 62-83. doi: 10.1177/109442810141004

[17]. Chuang, T., Chang, H., Lee, H., Chou, C., \& Doong, J. (2003). Virtual reality 
serves as a support technology in cardiopulmonary exercise testing. Presence, 12(3), 326- 351. doi: $10.1162 / 105474603765879567$

[18]. Cornick, J.E. \& Blascovich, J. (2015). Consequences of objective selfawareness during exercise. Health Psychology Open, 2(2), 1-9. doi: $10.1177 / 2055102915598088$

[19]. Cornick, J.E. \& Blascovich, J. (2016). Virtual reality and eating, diabetes and obesity. In C.D. Combs, J.A. Sokolowski, \& C.M. Banks (Eds.), The digital patient: Advancing healthcare, research, and education (pp. 181-198). Hoboken, NJ: Wiley \& Sons.

[20]. Dean, E., Cook, S., Keating, M., \& Murphy, J. (2009). Does this avatar make me look fat? Obesity and interviewing in Second Life. Journal for Virtual Worlds Research, 2(2), 4-11. doi: 10.4101/jvwr.v2i2.621

[21].Feltz, D., Short, S., \& Sullivan, P. (2008). Self-efficacy in sport: Research and strategies for working with athletes, teams, and coaches. International Journal of Sports Science and Coaching, 3(2), 293-295. doi: 10.1260/174795408785100699

[22]. Fox, J., \& Bailenson, J. N. (2009). Virtual self-modeling: The effects of vicarious reinforcement and identification on exercise behaviors. Media Psychology, 12(1), 1-25. doi: 10.1080/15213260802669474

[23]. Gao, Z., Chen, S., Pasco, D., \& Pope, Z. (2015). A meta-analysis of active video games on health outcomes among children and adolescents. Obesity Reviews, 16(9), 783-794.

[24]. Ginis, K. A. M., Jung, M. E., \& Gauvin, L. (2003). To see or not to see: Effects of exercising in mirrored environments on sedentary women's feeling states and self-efficacy. Health Psychology, 22(4), 354-361. doi: 10.1037/02786133.22.4.354

[25]. Hankonen, N., Absetz, P., Ghisletta, P., Renner, B., \& Uutela, A. (2010). Gender differences in social cognitive determinants of exercise adoption.
Psychology and Health, 25(1), 55-69. doi: 10.1080/08870440902736972

[26]. Hayes, A. F. (2012). PROCESS: A versatile computational tool for observed variable mediation, moderation, and conditional process modeling [Software]. Retrieved from http://www.afhayes.com/public/process 2012.pdf

[27]. Hayes, A. F. (2015). An index and test of linear moderated mediation. Multivariate Behavioral Research, 50(1), 1-22. doi: $10.1080 / 00273171.2014 .962683$

[28]. Higgins, E. Tory (1989). Selfdiscrepancy theory: What patterns of self-beliefs cause people to suffer? In L. Berkowitz, Advances in experimental social psychology (Vol. 22., pp. 93136). San Diego, CA: Academic Press.

[29]. Hutchinson, J., Sherman, T., Martinovic, N., \& Tenenbaum, G. (2008). The effect of manipulated selfefficacy on perceived and sustained effort. Journal of Applied Sport Psychology, 20(4), 457-472. doi: 10.1080/10413200802351151

[30]. Ijsselsteijn, W. A., Kort, Y. D., Westerink, J. H. D. M., Jager, M. D., \& Bonants, R. (2006). Virtual fitness: stimulating exercise behavior through media technology. Presence: Teleoperators and Virtual Environments, 15(6), 688-698. doi: 10.1162/pres.15.6.688

[31]. Johnston, J. D., Massey, A. P., \& DeVaneaux, C. (2012). Innovation in weight loss intervention programs: An examination of a 3D virtual world approach. System Science (HICSS), 2012 45th Hawaii International Conference, 2890-2899. doi: 10.1109/HICSS.2012.325

[32]. Jones, M., Meijen, C., McCarthy, P. J., \& Sheffield, D. (2009). A theory of challenge and threat states in athletes. International Review of Sport and Exercise Psychology, 2(2), 161-180. doi: 10.1080/17509840902829331

[33]. Kaminsky, L. A., Arena, R., Beckie, T. M., Brubaker, P. H., Church, T. S., 
Forman, D. E., ... Williams, M. A. (2013). The importance of cardiorespiratory fitness in the United States: the need for a national registry a policy statement from the American Heart Association. Circulation, 127(5), 652-662. doi: 10.1161/CIR.0b013e31827ee100

[34]. Katula, J.A. \& McAuley, E. (2001). The mirror does not lie: Acute exercise and self-efficacy. International Journal of Behavioral Medicine, 8(4), 319-326. doi: 10.1207/s15327558ijbm0804 6

[35]. Katula, J. A., McAuley, E., Mihalko, S. L., \& Bane, S. M. (1998). Mirror, mirror on the wall Exercise environment influences on self-efficacy. Journal of Social Behavior and Personality, 13(2), 319-332. Retrieved from http://search.proquest.com/docview/12 92283269?pq-origsite $=$ gscholar

[36]. Kelsey, R. M. (2004). Heart disease and reactivity. In N. B. Anderson (Ed.), Encyclopedia of health and behavior (pp. 510-517). Thousand Oaks, CA: Sage Publications.

[37]. Legrand, F. D., Joly, P. M., Bertucci, W. M., Soudain-Pineau, M. A., \& Marcel, J. (2011). Interactive-Virtual Reality (IVR) exercise: An examination of intask and pre-to-post exercise affective changes. Journal of Applied Sport Psychology, 23(1), 65-75. doi: 10.1080/10413200.2010.523754

[38]. Llewellyn, D., Sanchez, X., Asghar, A., \& Jones, G. (2008). Self-efficacy, risk taking, and performance in rock climbing. Personality and Individual Differences, 45(1), 75- 81. doi: 10.1016/j.paid.2008.03.001

[39]. Lyons, E. J., Tate, D. F., Komoski, S. E., Carr, P. M., \& Ward, D. S. (2012). Novel approaches to obesity prevention: Effects of game enjoyment and game type on energy expenditure in active video games. Journal of Diabetes, Science and Technology, 6(4), 839-848. doi: 10.1177/193229681200600415

[40]. Major, B., Hunger, J. M., Bunyan, D. P., \& Miller, C. T. (2014). The ironic effects of weight stigma. Journal of
Experimental Social Psychology, 51, 74-80. doi: 10.1016/j.jesp.2013.11.009

[41]. Mead, G.H. (1934). Mind, self and society form the standpoint of a social behaviourist. Chicago, IL: University of Chicago Press.

[42]. Mendes, W. B., Blascovich, J., Hunter, S. B., Lickel, B., \& Jost, J. T. (2007). Threatened by the unexpected: physiological responses during social interactions with expectancy-violating partners. Journal of Personality and Social Psychology, 92(4), 698-716. doi: 10.1037/0022-3514.92.4.698

[43]. Mendes, W.B., Blascovich, J., Lickel, B., \& Hunter, S. (2002). Challenge and threat during social interactions with White and Black men. Personality and Social Psychology Bulletin, 28(7), 939952.

doi:

$10.1177 / 014616720202800707$

[44]. Mendes, W. B., Blascovich, J., Major, B., \& Seery, M. (2001). Challenge and threat responses during downward and upward social comparisons. European Journal of Social Psychology, 31(5), 477-497. doi: 10.1002/ejsp.80

[45]. Muennig, P., Jia, H., Lee, R., \& Lubetkin, E. (2008). I think therefore I am: Perceived ideal weight as a determinant of health. American Journal of Public Health, 98(3), 501506. doi: 10.2105/AJPH.2007.114769

[46]. Ogden, C. L., Carroll, M. D., Kit, B. K., \& Flegal, K. M. (2014). Prevalence of childhood and adult obesity in the United States, 2011-2012. Journal of the American Medical Association, 311(8), 806-814. doi: 10.1001/jama.2014.732.

[47]. Plante, T. G., Aldridge, A., Bogden, R., \& Hanelin, C. (2003). Might virtual reality promote the mood benefits of exercise? Computers in Human Behavior, 19(4), 495-509. doi: 10.1016/S0747-5632(02)00074-2

[48]. Plante, T. G., Cage, C., Clements, S., \& Stover, A. (2006). Psychological benefits of exercise paired with virtual reality: Outdoor exercise energizes whereas indoor virtual exercise relaxes. 
International Journal of Stress Management, 13(1), 108-117. doi: 10.1037/1072-5245.13.1.108

[49]. Rizzo, A. S., Lange, B., Suma, E. A., \& Bolas, M. (2011). Virtual reality and interactive digital game technology: new tools to address obesity and diabetes. Journal of Diabetes Science and Technology, 5(2), 256-264. doi: $10.1177 / 193229681100500209$

[50]. Rouselle, J.G., Blascovich, J., Kelsey, R.M. (1995). Cardiorespiratory response under combined psychological and exercise stress. International Journal of Psychophysiology, 20(1), 4958. doi: 10.1016/0167-8760(95)00026$\mathrm{O}$

[51]. Rowell, L.B., Taylor, H.L., Wang, Y., \& Carlson, W.S. (1964). Saturation of arterial blood with oxygen during maximal exercise. Journal of Applied Physiology, 19(2), 284-286. Retrieved from

http://jap.physiology.org/content/19/2/2 84.short

[52]. Russell, W. D., \& Newton, M. (2008). Short-Term Psychological Effects of Interactive Video Game Technology Exercise on Mood and Attention. Educational Technology \& Society, 11(2), 294-308. Retrieved from http://www.ifets.info/journals/11_2/21. pdf

[53]. Samson, A., \& Solmon, M. (2011). Examining the sources of self-efficacy for physical activity within the sport and exercise domains. International Review of Sport and Exercise Psychology, 4(1), 70-89. doi: 10.1080/1750984X.2011.564643

[54]. Sherwood, A., Allen, M.T., Fahrenberg, J., Kelsey, R.M., Lovallo, W.R., \& van Doornen, L.J.P. (1990). Methodological guidelines for impedance cardiography, Psychophysiology, 27(1), 1-23. doi: 10.1111/j.1469-8986.1990.tb02171.x

[55]. Simonavice, E.M. (2008). Exercise barriers, self-efficacy, and stages of change. Perceptual and Motor Skills, 107(3), 946-950. doi: 10.2466/pms.107.3.946-950
[56]. Smith, D., \& Fernhall, B. (2010). Advanced cardiovascular exercise physiology. Champaign, IL: Human Kinetics.

[57]. Song, H., Kim, J., \& Lee, K. M. (2014). Virtual vs. real body in exergames: Reducing social physique anxiety in exercise experiences. Computers in Human Behavior, 36, 282-285. doi: 10.1016/j.chb.2014.03.059

[58]. Song, H., Peng, W., \& Lee, K. M. (2011). Promoting exercise selfefficacy with an exergame. Journal of Health Communication, 16(2), 148-162. doi: 10.1080/10810730.2010.535107

[59]. Strecher, V.J., McEvoy DeVellis, B., Becker, M.H., \& Rosenstock, I.M. (1986). The role of self efficacy in achieving health behavior change. Health Education Quarterly, 13(1), 7391. doi: 10.1177/109019818601300108

[60]. Tabachnick, B.G. \& Fidell, L.S. (2013).Using Multivariate Statistics $\left(^{\text {th }}\right.$ ed.). Upper Saddle River, NJ: Pearson Education.

[61]. Taylor, S. E., \& Brown, J. D. (1988). Illusion and well-being: a social psychological perspective on mental health. Psychological Bulletin, 103(2), 193-210. doi: 10.1037/00332909.103.2.193

[62]. Tomaka, J., Blascovich, J., Kelsey, R. M., \& Leitten, C. L. (1993). Subjective, physiological, and behavioral effects of threat and challenge appraisal. Journal of Personality and Social Psychology, 65(2), 248-260. doi: 10.1037/00223514.65.2.248

[63]. Tomaka, J., Blascovich, J., Kibler, J., \& Ernst, J. M. (1997). Cognitive and physiological antecedents of threat and challenge appraisal. Journal of Personality and Social Psychology, 73(1), 63-72. doi: 10.1037/00223514.73.1.63

[64]. Wasserman, K., Hansen, J., Sue, D.Y., Stringer, W.W., \& Whipp, B.J. (2004). Principles of exercise testing and interpretation including pathophysiology and clinical 
applications ( $4^{\text {th }}$ ed.). Philadelphia, PA:

Lippincott, Wilkins, \& Williams.

[65]. Wicklund, R.A., \& Duval, S. (1971). Opinion change and performance facilitation as a result of objective selfawareness. Journal of Experimental Social Psychology, 7(3), 319-342. doi: 10.1016/0022-1031(71)90032-1

[66].Yee, N., Bailenson, J. N., \& Ducheneaut, N. (2009). The Proteus effect: Implications of transformed digital self-representation on online and offline behavior. Communication Research, 36 (2), 285-312. doi: $10.1177 / 0093650208330254$ 


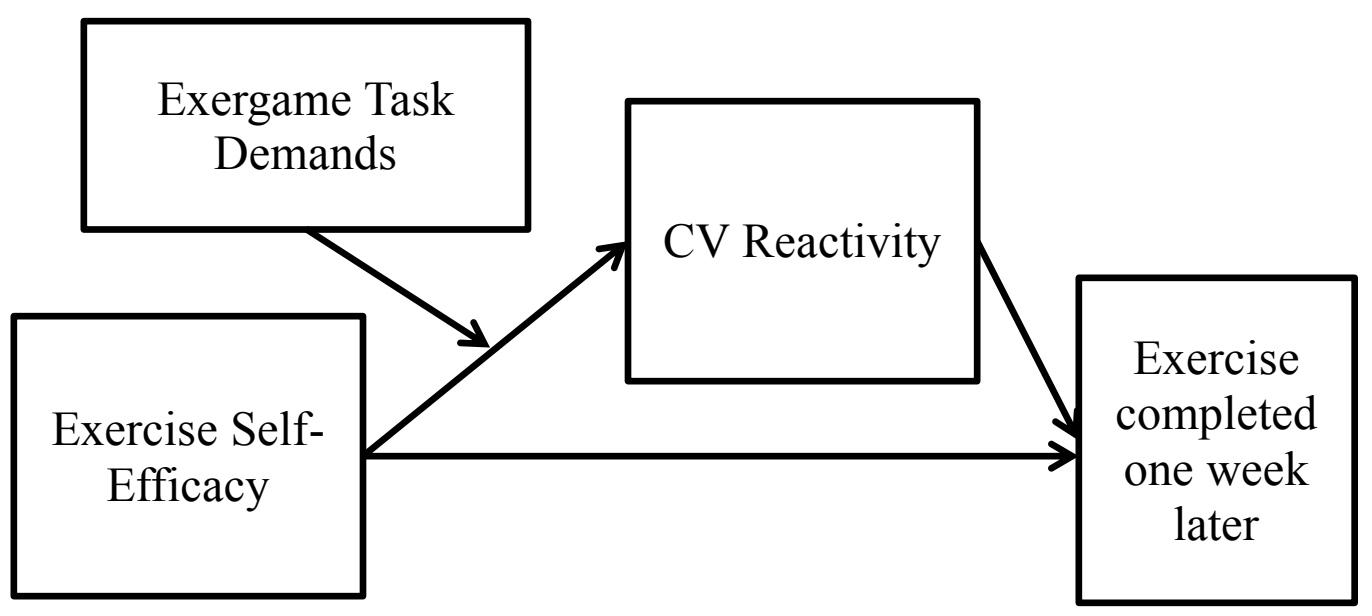

Figure 1. Theoretical model for the current study. 


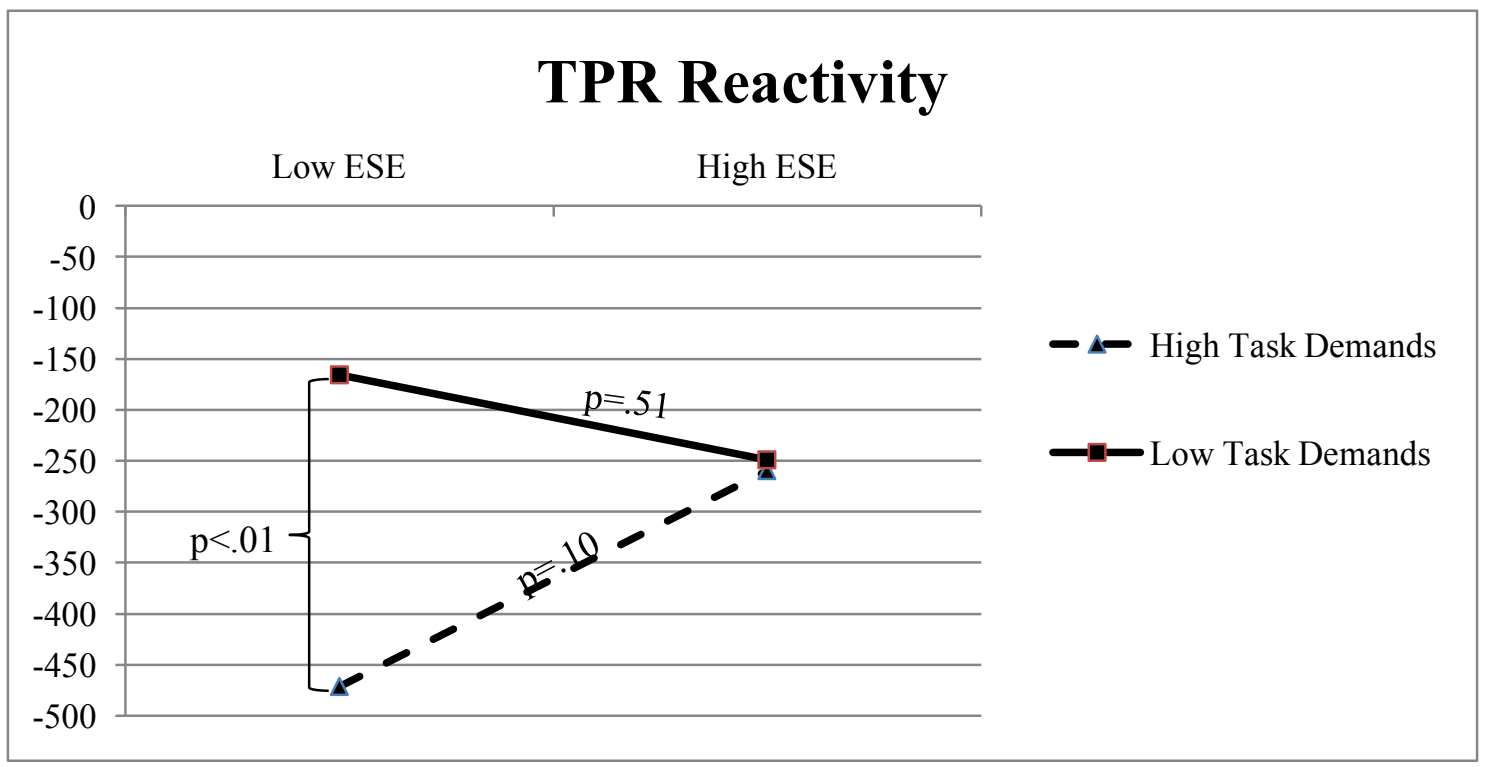

Figure 2. TPR reactivity values by exergame task demands condition and high and low exercise self-efficacy (ESE). More negative values indicate a challenge state of cardiovascular responding with an equal or greater amount of resources compared to task demands. 


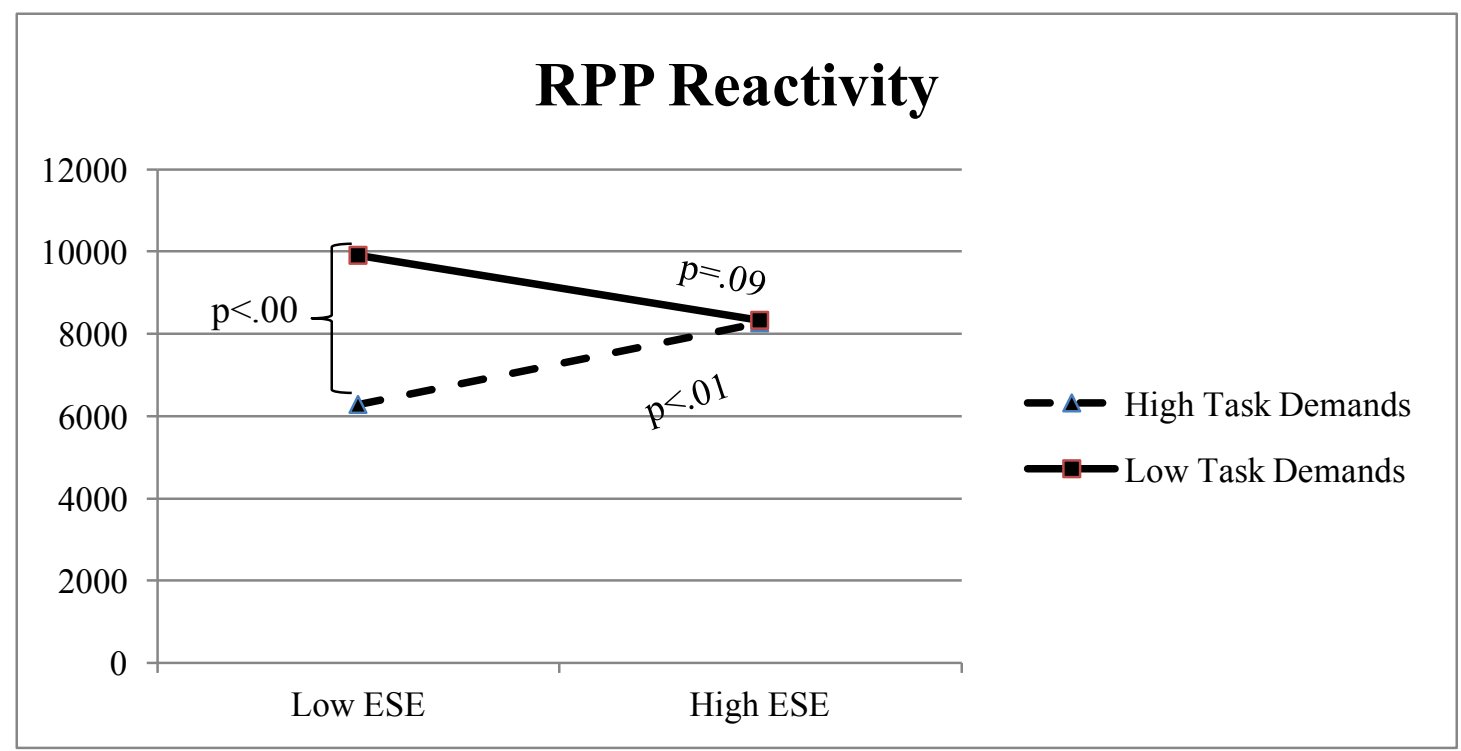

Figure 3. RPP reactivity values by exergame task demands condition and high and low exercise self-efficacy (ESE). 
Table 1

Summary of Means, Standard Deviations, and Missing Data for Scores on ESE, CO, $T P R, R P P$ and Strenuous Exercise by Condition

\begin{tabular}{|c|c|c|c|c|c|c|c|c|}
\hline & \multicolumn{4}{|c|}{ Low Task Demands } & \multicolumn{4}{|c|}{ High Task Demands } \\
\hline & $n$ & $M$ & $S D$ & Missing & $n$ & $M$ & $S D$ & Missing \\
\hline ESE & 41 & 5.31 & 1.81 & 4 & 40 & 5.24 & 1.83 & 4 \\
\hline $\mathrm{CO}$ reactivity & 41 & 19.96 & 22.92 & 4 & 41 & 18.76 & 21.72 & 3 \\
\hline TPR reactivity & 38 & -210.92 & 373.50 & 7 & 40 & -365.42 & 349.65 & 4 \\
\hline RPP reactivity & 38 & 9022.74 & 2390.50 & 7 & 40 & 7563.94 & 3324.25 & 4 \\
\hline $\begin{array}{l}\text { Strenuous } \\
\text { exercise }\end{array}$ & 40 & 2.59 & 1.33 & 5 & 42 & 1.91 & 1.70 & 2 \\
\hline
\end{tabular}

Note . $\mathrm{ESE}=$ Exercise self-efficacy; $\mathrm{CO}=$ cardiac output; $\mathrm{TPR}=$ total peripheral resistance; $\mathrm{RPP}=$ rate pressure product. 


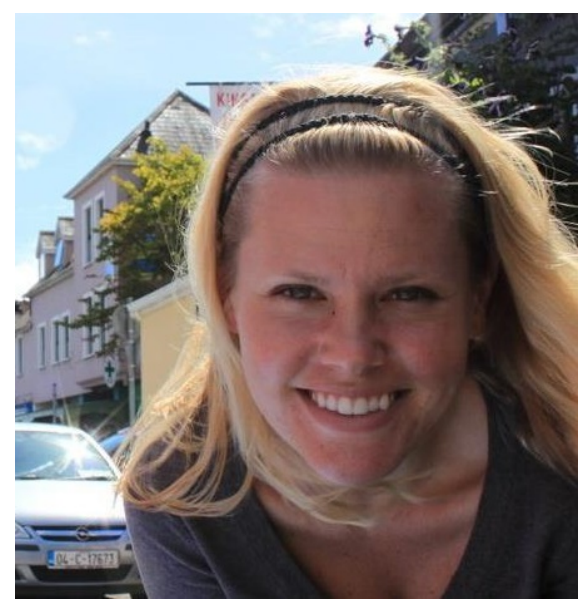

Jessica Cornick is a recent Ph.D. graduate from the Psychological and Brain Sciences department at UCSB. For her dissertation, Jessica examined the influential nature of avatars on the selfconcept framework. In particular, she explored whether the influence was uni-directional (the user dictating avatar behavior) or bi-directional (the avatar influences the user in previously undocumented ways) and how this influence impacted future decision making and behavior.

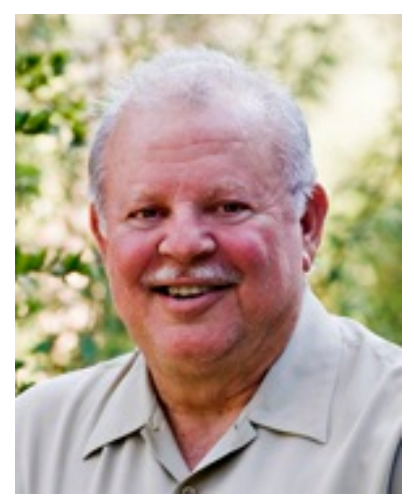

Jim Blascovich is the director and co-founder of the Research Center for Virtual Environments at the University of California, Santa Barbara, where he is a Distinguished Professor in the Department of Psychological and Brain Sciences. Professor Blascovich has served as the president of international scientific societies, including the Society for Personality and Social Psychology and the Society for Experimental Social Psychology, and he has been invited to lecture on social neuroscience and virtual reality topics worldwide. 